\title{
Erythritol-enriched powder and oral biofilm regrowth on dental implants: an in vitro study
}

\author{
Patricia Amate-Fernández ${ }^{1}$, Rui Figueiredo ${ }^{2,3}$, Vanessa Blanc ${ }^{4}$, Gerard Àlvarez ${ }^{5}$, Rubén León ${ }^{6}$, Eduard \\ Valmaseda-Castellón ${ }^{2,3}$
}

${ }^{1}$ DDS, PhD student. Faculty of Medicine and Health Sciences of the University of Barcelona, Spain

${ }^{2}$ DDS, MS, PhD. Tenured lecturer. Oral Surgery and Implantology Department, Faculty of Medicine and Health Sciences of the University of Barcelona, Spain

${ }^{3}$ Researcher at the IDIBELL Institute, Barcelona, Spain

${ }^{4}$ MS, PhD. Microbiology Department Director. Dentaid Research Center, Cerdanyola del Vallès, Barcelona, Spain

${ }^{5}$ MS, PhD. Microbiology Department Researcher. Dentaid Research Center, Cerdanyola del Vallès, Barcelona, Spain

${ }^{6}$ MS, PhD. R\&D Manager. Dentaid Research Center, Cerdanyola del Vallès, Barcelona, Spain

Correspondence:

Faculty of Medicine and Health Sciences, University of Barcelona

Campus de Bellvitge UB, Facultat de Medicina i Ciències de la Salut, Odontologia

C/ Feixa Llarga, s/n, Pavelló Govern, 2a planta, Despatx 2.9

08907, L'Hospitalet de Llobregat, Barcelona, Spain

ruibarbosa@ub.edu

Received: $27 / 01 / 2021$

Accepted: 01/03/202

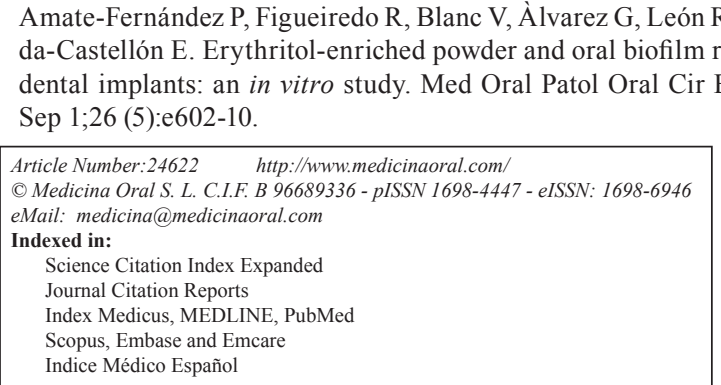

\begin{abstract}
Backgroud: Peri-implant mucositis and peri-implantitis are the main biological complications associated with dental implants. Since most authors agree that bacteria play a major etiological role, the main aims of this study were to determine if a formulation of erythritol and chlorhexidine applied with an air polishing system inhibits biofilm re-growth over dental implants and to compare the decontamination capacity of this therapy with that of mechanical removal by saline and gauze.

Material and Methods: A multispecies biofilm (P. gingivalis, A. actinomycetemcomitans, F. nucleatum, A. naeslundii, V. parvula and S. oralis) was grown for 14 days on 52 dental implants in an artificial mouth. These implants were divided into three groups according to the applied treatment: 14 negative control (CON), 19 erythritolchlorhexidine (ERY) and 19 gauze with saline (GAU) samples. Twelve dental implants from the ERY and GAU groups and 8 implants from the CON group were re-incubated for 7 additional days after treatment. The bacterial count was performed by quantitative polymerase chain reaction (qPCR) using propidium monoazide (PMA). A descriptive and bivariate analysis of the data was performed.

Results: The erythritol and chlorhexidine formulation significantly inhibited biofilm regrowth in comparison with the mechanical treatment (GAU), since a significant decrease in all the species was observed in the ERY group (except for Aggregatibacter actinomycetemcomitans). The antibiofilm and antibacterial capacity of the two active treatment groups (ERY and GAU) was similar for a 14 days multispecies in vitro biofilm, except for the lower count of $A$. naeslundii in the GAU group.
\end{abstract}


Conclusions: The use of erythritol powder with chlorhexidine applied with an air polishing system reduces biofilm regrowth over dental implants when compared with mechanical removal by saline and gauze. This effect might be beneficial for patients included in peri-implant maintenance programs.

Key words: Dental implants, biofilms, peri-implantitis, erythritol, chlorhexidine.

\section{Introduction}

Dental implants have become the gold standard when aiming at reconstruction of missing teeth. Several studies have proven dental implants to be a reliable alternative for providing function and aesthetics with long-term success. However, with increasing numbers of fixtures being installed yearly, there has also been a significant increase in peri-implant diseases (1).

Mucositis and peri-implantitis are the main biological complications associated with dental implants $(2,3)$. Data indicate that bacteria play a major etiological role in the development of these complications, several treatment strategies have been developed with the aim of reducing the bacterial count, decontaminating the implant surface and removing the biofilm (4). Biofilms are surface-adhered microbial communities embedded in a self-produced matrix (5). These organized communities represent a significant health risk due to their resistance to host-defense mechanisms and their decreased susceptibility to conventional antimicrobials. Biofilm-mediated resistance has been attributed to impaired penetration of antimicrobials through the matrix, increased expression of drug-resistance genes, and reduced metabolic activity of cells residing in the biofilm. Because of their involvement in bacterial infections in humans, biofilms have been the subject of intensive research for many years (5).

Polymerase chain reaction (PCR) techniques have shown several advantages over traditional microbiologic culture methods. They are faster and have a higher specificity and sensitivity for identifying and quantifying oral bacteria. Nevertheless, PCR might overestimate the number of active bacteria because it does not differentiate DNA coming from live or dead microorganisms. Thus, the use of propidium monoazide (PMA) is of great interest since it allows to detect cell membrane integrity, distinguishing viable and irreversibly damaged cells (6-10).

Regarding the treatment of peri-implant diseases, a variety of different approaches have been proposed, ranging from non-surgical therapy to laser disinfection or to surgical treatments with either resective or regenerative approaches (11). The ideal treatment should focus not only on removing pathogens from the implant surfaces, but also on preventing bacterial regrowth over the area. This is a crucial issue, since one of the main treatment goals should be to prevent the adhesion of primary colonizers to the recently decontaminated implant surfaces.
However, knowledge on this process is still very scarce. A minimally abrasive powder containing erythritol and $3 \%$ chlorhexidine has been considered a promising treatment option for the removal of subgingival biofilm $(12,13)$. A recent systematic review and meta-analysis showed that erythritol/chlorhexidine was superior or equal to other methods when applied over contaminated implant surfaces, and was more biocompatible (14). However, few studies have been performed to evaluate the anti-biofilm regrowth properties of this formulation. For this reason, the present in vitro study was conducted with the following aims: to determine if a formulation of erythritol and 3\% chlorhexidine applied with an air polishing system inhibits biofilm regrowth over dental implants and to compare the decontamination capacity of this therapy with those of mechanical removal with saline and gauze.

\section{Material and Methods}

A randomized, single-blind, in vitro study was carried out. Fifty-two dental implants (Avinent, Santpedor, Barcelona, Spain) were subjected to in vitro multi-species biofilm formation in the microbiology department of the Dentaid Research Center (Dentaid SL, Cerdanyola del Vallès, Spain). Decontamination of the implants was randomly performed either with erythritol powder with $3 \%$ of chlorhexidine (Air Flow Powder Plus, EMS, Nyon, Switzerland) using an air-flow device (EMS, Nyon, Switzerland) or with a gauze swab with sterile saline solution. A single clinician performed these procedures for the time considered necessary to remove the biofilm adequately according to the clinician's professional criterion. The implants were then coded to avoid bias in the microbiology analysis.

- Biofilm development on implant surfaces

Oral biofilms were grown in an artificial mouth model in an anaerobic atmosphere (15) using the following bacterial species: Streptococcus oralis DSM 20627, Veillonella parvula NCTC 11810, Actinomyces naeslundii DSM 17233, Fusobacterium nucleatum DSM 20482, Porphyromonas gingivalis ATCC 33277 and Aggregatibacter actinomycetemcomitans DSMZ 8324. The bacteria were kept on blood agar plates (Oxoid No. 2; Oxoid Ltd, Basingstoke, UK) with 5\% horse blood, $5 \mathrm{mg} / \mathrm{L}$ hemin and $1 \mathrm{mg} / \mathrm{L}$ menadione at $37^{\circ} \mathrm{C}$ under anaerobic conditions, while BHI-II medium was employed for both the liquid cultures and biofilm growth. All the species were inoculated simultaneously from exponen- 
tial phase cultures, except for $P$. gingivalis, which was inoculated 24 hours previously in the bioreactor. The bacteria were kept in a continuous culture for 5 days. Subsequently, they were transferred to the device where the implants were located, bathing them totally for 14 days at a flow rate of $30 \mathrm{~mL} / \mathrm{h}$, in anaerobic conditions, at $37^{\circ} \mathrm{C}$ and $\mathrm{pH} 7.2(15)$.

- Experimental treatments

After 14 days in the artificial mouth, the implants were removed from the device and assigned randomly, using a computer-generated sequence (www.randomization. com, accessed on February 18, 2019), to one of the study groups: erythritol powder with $3 \%$ of chlorhexidine (ERY group); gauze with sterile saline (GAU group) or negative control (CON group) (Fig. 1). Fourteen negative control implants were immersed three times in phosphate buffered saline (PBS) $(137 \mathrm{mM} \mathrm{NaCl}, 2.7$ $\left.\mathrm{mM} \mathrm{KCl}, 10 \mathrm{mM} \mathrm{Na}_{2} \mathrm{HPO}_{4}, 2 \mathrm{mM} \mathrm{KH}_{2} \mathrm{PO}_{4}, \mathrm{pH} 7.4\right)$. Of these, 6 were then processed for genomic DNA extraction and 8 were placed in a new sterile vessel for regrowth. In the ERY group, 19 implants were treated with chlorhexidine-enriched erythritol powder, applied with an air-polishing device. Seven were processed for genomic DNA extraction and 12 were re-incubated for 7 days after treatment. In the GAU group, the same number of implants were treated mechanically (gauze with sterile saline) and analyzed (Fig. 1) or used for regrowth.
The regrowth process took place under the same conditions as the initial biofilm development. After this incubation time, all the regrowth implants were processed for genomic DNA extraction.

-Propidium monoazide (PMA) treatment, DNA extraction and quantitatve PCR (qPCR)

qPCR was used to determine the total number of cells of each species that formed the biofilms on the implants, while the live cell count was determined by PMA-qPCR (16). For this purpose, the implants were washed by immersing them three times in PBS. The biofilms were dispersed using a vortex for 5 minutes in $1 \mathrm{~mL}$ of PBS. The PMA treatment prior to genomic DNA extraction was performed as described by Àlvarez et al. (16). Genomic DNA extraction was effected using the QIAamp DNA Mini Kit (Qiagen, Hilden, Germany), following a previously published protocol (15). Quantitative PCR was performed with a LightCycler 480 II Instrument and the LightCycler 480 II Probes Master kit (Roche Diagnostics, Penzberg, Germany) and specific primers (Invitrogen Life Technologies, Carlsbad, CA, USA) and probes (Applied Biosystems, UK and Roche Diagnostics, Penzberg, Germany) were used. Data analysis was performed with LightCycler 480 Software 1.5 (Roche Diagnostics) using the second derivative maxim method. The $\mathrm{qPCR}$ reaction was conducted using an initial cycle of $95^{\circ} \mathrm{C}$ for $10 \mathrm{~min}$ utes, followed by 40 cycles of denaturation at $95^{\circ} \mathrm{C}$ for 10

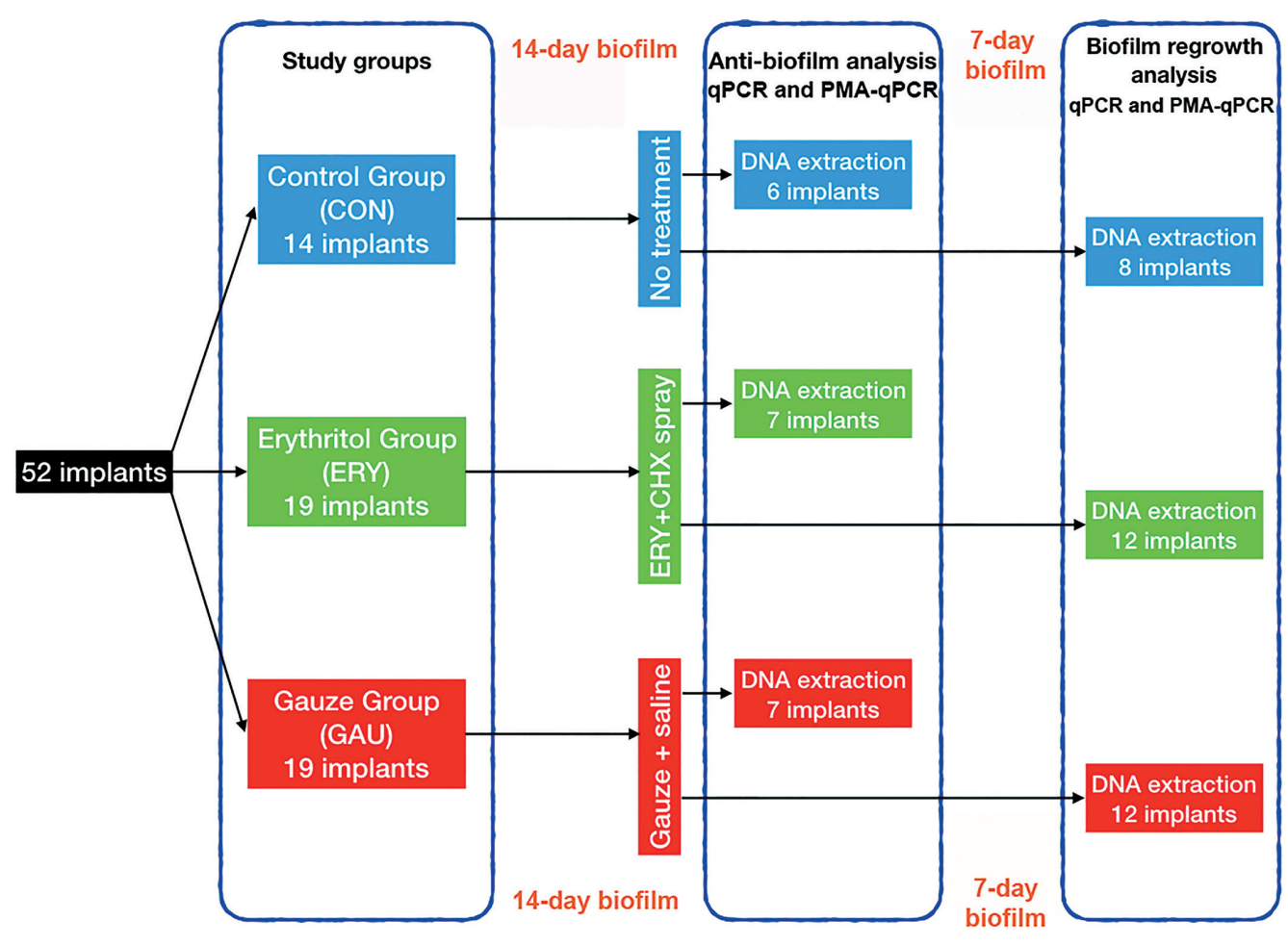

qPCR: Quantitative polymerase chain reaction; PMA: Propidium monoazide.

Fig. 1:Flow diagram of the present study. 
seconds, annealing at $60{ }^{\circ} \mathrm{C}$ for 30 seconds, and extension at $72^{\circ} \mathrm{C}$ for 1 second. Standard curves for each bacterial species were developed as described in Àlvarez et al. (16). - Microscopic analysis

Two implants from each group were randomly selected for analysis by confocal laser scanning microscopy (Leica TCS SP5, Leica Microsystems, Heidelberg, Germany). After a washing procedure to remove nonadhered bacteria, the implant biomass was dyed with SYTO9 nucleic acid stain (Molecular Probes, Eugene, OR, USA) at room temperature in the dark for $10 \mathrm{~min}$ utes. Six fields per implant were acquired with a 10x objective, with the white laser set at $482 \mathrm{~nm}$. Imaris ${ }^{\circledR}$ v.7.1 software (Bitplane AG, Badenerstrasse, Zurich, Switzerland) was used to obtain a 3D reconstruction of each field from the optical sections. Due to the results found in the ERY group (recolonization), 2 negative control implants and 2 implants treated with erythritol were examined under a scanning electron microscope (Merlin FE$\mathrm{SEM}^{\circledR}$, Carl Zeiss, Oberkochen, Germany) at 30,000x in order to detect surface alterations after treatment. - Statistical analysis

A descriptive analysis of the data was performed with the Statistical Package for Social Sciences software (SPSS v22.0; IBM Corp, Armonk, New York). Kruskal Wallis tests and Mann-Whitney U-tests were employed to detect differences between the 3 groups. The level of significance was set at $p<0.05$.

\section{Results}

The results concerning the effect of the 3 treatments on a 14-day multispecies biofilm can be observed in Table 1. The groups showed similar qPCR results for most of the bacteria. However, the mechanical treatment (GAU group) had a lower total count (qPCR) of A. naeslundii and $P$. gingivalis than the $\mathrm{CON}$ group ( $p=0.01$ and $p=0.026$, respectively). No significant differences were found when comparing the two active treatment groups (ERY and GAU), except in A. naeslundii, which had a lower bacterial count in the GAU group ( $p=0.022$; Table 1). Regarding the PMA-qPCR results, the number of live $P$. gingivalis cells was significantly lower in the ERY group than in the CON group, while the number of live $A$. actinomycetemcomitans cells was lower in both treatment groups (ERY and GAU) than in the CON group.

The outcomes of the second phase of the study (biofilm regrowth after treatment), which are related with the main study aim, are presented in Table 2. In comparison with the standard mechanical therapy (GAU), the ERY group was found to present a significant reduction in biofilm regrowth after therapy for all species except $A$. actinomycetemcomitans (qPCR and PMA-qPCR) and S. oralis (PMA-qPCR). To evaluate the resilience of the biofilms after application of the therapies, the PMA-qPCR ratios (following treatment after 14 days of biofilm growth and after 7 days of biofilm regrowth) were compared (Fig. 2, Fig. 3).

Table 1: Main results for the 3 treatment groups (ERY, GAU and CON) in the first phase of the study (after treatment following 14 days of biofilm growth) stratified by logarithms of bacterial species.

\begin{tabular}{|c|c|c|c|c|c|c|c|c|c|c|}
\hline \multirow{3}{*}{$\begin{array}{l}\text { Bacterial species } \\
\text { (14-day biofilm) }\end{array}$} & \multicolumn{5}{|c|}{ qPCR } & \multicolumn{5}{|c|}{ PMA-qPCR } \\
\hline & ERY & GAU & $\mathrm{CON}$ & \multicolumn{2}{|c|}{ Bivariate } & ERY & GAU & $\mathrm{CON}$ & \multicolumn{2}{|c|}{ Bivariate } \\
\hline & \multicolumn{3}{|c|}{ Mean (SD) } & \multicolumn{2}{|l|}{$p$-value } & \multicolumn{3}{|c|}{ Mean $(S D)$} & \multicolumn{2}{|c|}{ p-value } \\
\hline \multirow[t]{3}{*}{ S. oralis } & \multirow{3}{*}{$\begin{array}{c}5.59 \\
(0.35)\end{array}$} & \multirow{3}{*}{$\begin{array}{c}5.23 \\
(0.22)\end{array}$} & \multirow{3}{*}{$\begin{array}{c}5.74 \\
(0.27)\end{array}$} & ERY vs. GAU & 0.259 & \multirow{3}{*}{$\begin{array}{l}5.56 \\
(0.56)\end{array}$} & \multirow{3}{*}{$\begin{array}{c}4.12 \\
(1.81)\end{array}$} & \multirow{3}{*}{$\begin{array}{c}5.37 \\
(0.28)\end{array}$} & ERY vs. GAU & 0.234 \\
\hline & & & & ERY vs. CON & 0.945 & & & & ERY vs. CON & 0.639 \\
\hline & & & & GAU vs. CON & 0.295 & & & & GAU vs. CON & 0.931 \\
\hline \multirow[t]{3}{*}{ V.parvula } & \multirow{3}{*}{$\begin{array}{c}6.28 \\
(1.35)\end{array}$} & \multirow{3}{*}{$\begin{array}{c}6.22 \\
(0.53)\end{array}$} & \multirow{3}{*}{$\begin{array}{c}6.51 \\
(0.38)\end{array}$} & ERY vs. GAU & 0.259 & \multirow{3}{*}{$\begin{array}{c}6.30 \\
(0.69)\end{array}$} & \multirow{3}{*}{$\begin{array}{c}4.90 \\
(1.58)\end{array}$} & \multirow{3}{*}{$\begin{array}{c}6.01 \\
(0.18)\end{array}$} & ERY vs. GAU & 0.343 \\
\hline & & & & ERY vs. CON & 0.445 & & & & ERY vs. CON & 0.639 \\
\hline & & & & GAU vs. CON & 0.945 & & & & GAU vs. CON & 0.841 \\
\hline \multirow[t]{3}{*}{ A. naeslundii } & \multirow{3}{*}{$\begin{array}{c}4.67 \\
(0.42)\end{array}$} & \multirow{3}{*}{$\begin{array}{c}4.09 \\
(0.27)\end{array}$} & \multirow{3}{*}{$\begin{array}{c}5.37 \\
(0.72)\end{array}$} & ERY vs. GAU & 0.022 & \multirow{3}{*}{$\begin{array}{c}4.07 \\
(0.53)\end{array}$} & \multirow{3}{*}{$\begin{array}{c}3.08 \\
(1.56)\end{array}$} & \multirow{3}{*}{$\begin{array}{c}3.97 \\
(0.15)\end{array}$} & ERY vs. GAU & 0.445 \\
\hline & & & & ERY vs. CON & 0.315 & & & & ERY vs. CON & 0.755 \\
\hline & & & & GAU vs. CON & 0.010 & & & & GAU vs. CON & 0.931 \\
\hline \multirow[t]{3}{*}{ F. nucleatum } & \multirow{3}{*}{$\begin{array}{c}5.75 \\
(0.38)\end{array}$} & \multirow{3}{*}{$\begin{array}{c}5.52 \\
(0.48)\end{array}$} & & ERY vs. GAU & 0.805 & 5.55 & 4.40 & 5.59 & ERY vs. GAU & 0.128 \\
\hline & & & $(0.91)$ & ERY vs. CON & 1.000 & $(0.50)$ & $(1.14)$ & $(0.42)$ & ERY vs. CON & 1.000 \\
\hline & & & & GAU vs. CON & 0.836 & & & & GAU vs. CON & 0.149 \\
\hline$P$. gingivalis & 5.35 & 5.13 & 5.82 & ERY vs. GAU & 0.318 & 4.63 & 4.12 & 5.52 & ERY vs. GAU & 0.445 \\
\hline & $(0.52)$ & $(0.46)$ & $(0.26)$ & ERY vs. CON & 0.073 & $(0.42)$ & $(1.35)$ & $(0.06)$ & ERY vs. CON & 0.003 \\
\hline & & & & GAU vs. CON & 0.014 & & & & GAU vs. CON & 0.009 \\
\hline A. actinomycetem- & 5.40 & 5.15 & 5.83 & ERY vs. GAU & 0.805 & 4.53 & 3.34 & 5.11 & ERY vs. GAU & 0.383 \\
\hline comitans & $(0.57)$ & $(0.73)$ & $(0.15)$ & ERY vs. CON & 0.534 & $(0.40)$ & $(1.31)$ & $(0.22)$ & ERY vs. CON & 0.003 \\
\hline & & & & GAU vs CON & 0.181 & & & & GAU vs CON & 0.343 \\
\hline
\end{tabular}

qPCR: quantitative polymerase chain reaction; PMA: propidium monoazide; ERY: erythritol powder with 3\% of chlorhexidine group; GAU: gauze with sterile saline group; CON: negative control group; SD: Standard deviation. 
Table 2: Main results for the 3 treatment groups (ERY, GAU and CON) in the second phase of the study (after 7 days of biofilm regrowth following treatment), stratified by logarithms of bacterial species.

\begin{tabular}{|c|c|c|c|c|c|c|c|c|c|c|}
\hline \multirow{3}{*}{$\begin{array}{l}\text { Bacterial species } \\
\text { (7-day biofilm } \\
\text { regrowth) }\end{array}$} & \multicolumn{5}{|c|}{ qPCR } & \multicolumn{5}{|c|}{ PMA-qPCR } \\
\hline & ERY & GAU & $\mathrm{CON}$ & \multicolumn{2}{|l|}{ Bivariate } & ERY & GAU & $\mathrm{CON}$ & \multicolumn{2}{|c|}{ Bivariate } \\
\hline & \multicolumn{3}{|c|}{ Mean (SD) } & \multicolumn{2}{|l|}{$p$-value } & \multicolumn{3}{|c|}{ Mean (SD) } & \multicolumn{2}{|c|}{ p-value } \\
\hline \multirow[t]{3}{*}{ S. oralis } & \multirow{3}{*}{$\begin{array}{c}4.70 \\
(1.26)\end{array}$} & \multirow{3}{*}{$\begin{array}{c}5.68 \\
(0.51)\end{array}$} & \multirow{3}{*}{$\begin{array}{c}6.31 \\
(0.43)\end{array}$} & ERY vs. GAU & 0.006 & \multirow{3}{*}{$\begin{array}{c}4.60 \\
(0.41)\end{array}$} & \multirow{3}{*}{$\begin{array}{c}5.04 \\
(0.99)\end{array}$} & \multirow{3}{*}{$\begin{array}{c}5.12 \\
(2.17)\end{array}$} & ERY vs. GAU & 0.203 \\
\hline & & & & ERY vs. CON & 0.000 & & & & ERY vs. CON & 0.109 \\
\hline & & & & GAU vs. CON & 0.017 & & & & GAU vs. CON & 0.100 \\
\hline \multirow[t]{3}{*}{ V. parvula } & \multirow{3}{*}{$\begin{array}{c}6.28 \\
(0.48)\end{array}$} & \multirow{3}{*}{$\begin{array}{c}6.77 \\
(0.34)\end{array}$} & \multirow{3}{*}{$\begin{array}{c}7.29 \\
(0.24)\end{array}$} & ERY vs. GAU & 0.010 & \multirow{3}{*}{$\begin{array}{c}5.15 \\
(0.50)\end{array}$} & \multirow{3}{*}{$\begin{array}{c}5.97 \\
(0.45)\end{array}$} & \multirow{3}{*}{$\begin{array}{c}6.94 \\
(0.18)\end{array}$} & ERY vs. GAU & 0.001 \\
\hline & & & & ERY vs. CON & 0.000 & & & & ERY vs. CON & 0.000 \\
\hline & & & & GAU vs. CON & 0.001 & & & & GAU vs. CON & 0.000 \\
\hline \multirow[t]{3}{*}{ A. naeslundii } & \multirow{3}{*}{$\begin{array}{c}4.23 \\
(1.09)\end{array}$} & \multirow{3}{*}{$\begin{array}{c}5.00 \\
(0.41)\end{array}$} & \multirow{3}{*}{$\begin{array}{c}5.06 \\
(1.04)\end{array}$} & ERY vs. GAU & 0.005 & \multirow{3}{*}{$\begin{array}{c}3.15 \\
(0.34)\end{array}$} & \multirow{3}{*}{$\begin{array}{c}4.01 \\
(0.59)\end{array}$} & \multirow{3}{*}{$\begin{array}{c}4.87 \\
(0.80)\end{array}$} & ERY vs. GAU & 0.036 \\
\hline & & & & ERY vs. CON & 0.031 & & & & ERY vs. CON & 0.022 \\
\hline & & & & GAU vs. CON & 0.238 & & & & GAU vs. CON & 0.070 \\
\hline \multirow[t]{3}{*}{ F. nucleatum } & \multirow{3}{*}{$\begin{array}{c}4.37 \\
(1.34)\end{array}$} & \multirow{3}{*}{$\begin{array}{c}5.92 \\
(0.38)\end{array}$} & 6.73 & ERY vs. GAU & 0.000 & 4.39 & 4.70 & 6.32 & ERY vs. GAU & 0.020 \\
\hline & & & $(0.36)$ & ERY vs. CON & 0.000 & $(0.42)$ & $(0.55)$ & $(0.81)$ & ERY vs. CON & 0.000 \\
\hline & & & & GAU vs. CON & 0.001 & & & & GAU vs. CON & $\mathbf{0 . 0 0 7}$ \\
\hline P. gingivalis & 4.67 & 5.44 & 6.46 & ERY vs. GAU & 0.011 & 5.03 & 5.30 & 6.07 & ERY vs. GAU & 0.009 \\
\hline & $(1.60)$ & $(0.98)$ & $(1.52)$ & ERY vs. CON & 0.041 & $(0.65)$ & $(1.18)$ & $(1.84)$ & ERY vs. CON & 0.203 \\
\hline & & & & GAU vs. CON & 0.041 & & & & GAU vs. CON & 0.208 \\
\hline A. actinomycetem- & 5.19 & 5.58 & 6.19 & ERY vs. GAU & 0.091 & 4.52 & 3.97 & 5.95 & ERY vs. GAU & 0.880 \\
\hline comitans & $(0.73)$ & $(0.51)$ & $(0.87)$ & ERY vs. CON & 0.026 & $(0.42)$ & $(1.23)$ & $(0.74)$ & ERY vs. CON & 0.020 \\
\hline & & & & GAU vs. CON & 0.031 & & & & GAU vs. CON & 0.025 \\
\hline
\end{tabular}

qPCR: quantitative polymerase chain reaction; PMA: propidium monoazide; ERY: erythritol powder with 3\% of chlorhexidine group; GAU: gauze with sterile saline group; CON: negative control group; SD: Standard deviation.

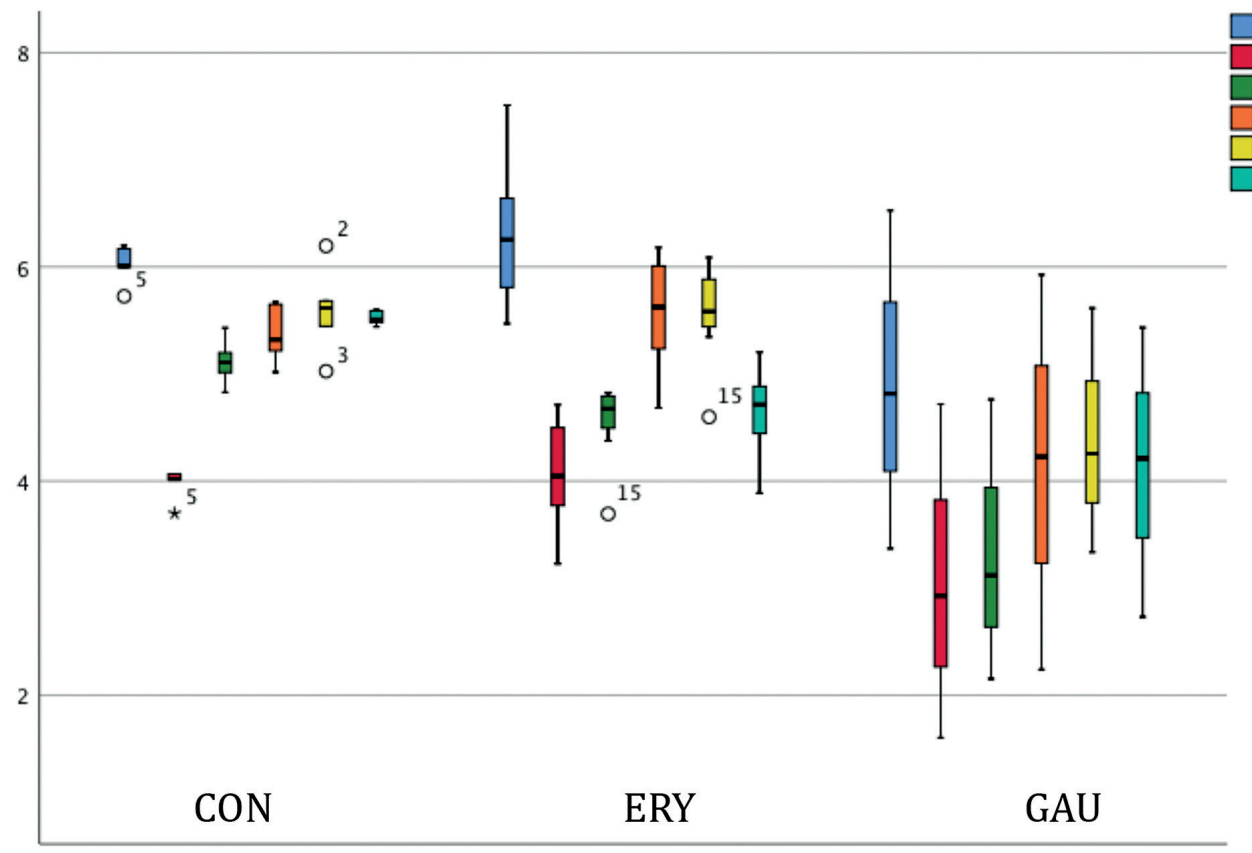

CON: Control group; GAU: Gauze group; ERY: Erythritol and chlorhexidine group; logPMAVp: Logarithm of Veionella parvula count with PMA-qPCR; $\log$ PMAAn:; Logarithm of Actinomyces naeslundii count with PMAqPCR; logPMAAa: Logarithm of Aggregatibacter actinomycetemcomitans count with PMA-qPCR; $\log$ PMASo: Logarithm of Streptococcus oralis count with PMA-qPCR; $\log$ PMAFn: Logarithm of Fusobacterium nucleatum count with PMA-qPCR; logPMAPg: Logarithm of Porphyromonas gingivalis count with PMA-qPCR; Outlier $\left({ }^{\circ}\right)$; extreme $(*)$.

Fig. 2: Comparison between the PMA-qPCR ratios of the 3 groups following treatment of a 14-day biofilm. 




GAU: Gauze group; ERY: Erythritol and chlorhexidine group; logPMAVp: Logarithm of Veionella parvula count with PMA-qPCR; $\log$ PMAAn:; Logarithm of Actinomyces naeslundii count with PMA-qPCR; $\log P M A A a:$ Logarithm of Aggregatibacter actinomycetemcomitans count with PMA-qPCR; $\log$ PMASo: Logarithm of Streptococcus oralis count with PMA-qPCR; $\log$ PMAFn: Logarithm of Fusobacterium nucleatum count with PMAqPCR; logPMAPg: Logarithm of Porphyromonas gingivalis count with PMA-qPCR; Outlier value $\left({ }^{\circ}\right)$; Extreme value $(*)$.

Fig. 3: Comparison between the PMA-qPCR ratios of the 2 active groups after therapy and 7-day biofilm regrowth.

The ERY biofilms showed the lowest ratios for most of the species, indicating low regeneration of the biofilm after this treatment. The confocal optical microscope images also support these results, since the biofilm coverage area was smaller on the ERY group implants (Fig. 4).

Scanning electronic microscopy (SEM) disclosed that the 2 implants of the ERY group displayed attached particles of approximately $0.1 \mu \mathrm{m}$ in size firmly attached to the implant surface. These particles were not found in the negative control implants.

\section{Discussion}

The present study shows that applying an erythritolenriched powder with $3 \%$ of chlorhexidine through an air-flow device inhibits biofilm regrowth on dental implants in comparison with debridement with a gauze with sterile saline solution. However, these therapies have proved to give similar results for removing already established biofilms.

This research has some limitations that must be mentioned. Firstly, the in vitro biofilm employed is not exactly the same as the one that a clinician might find in

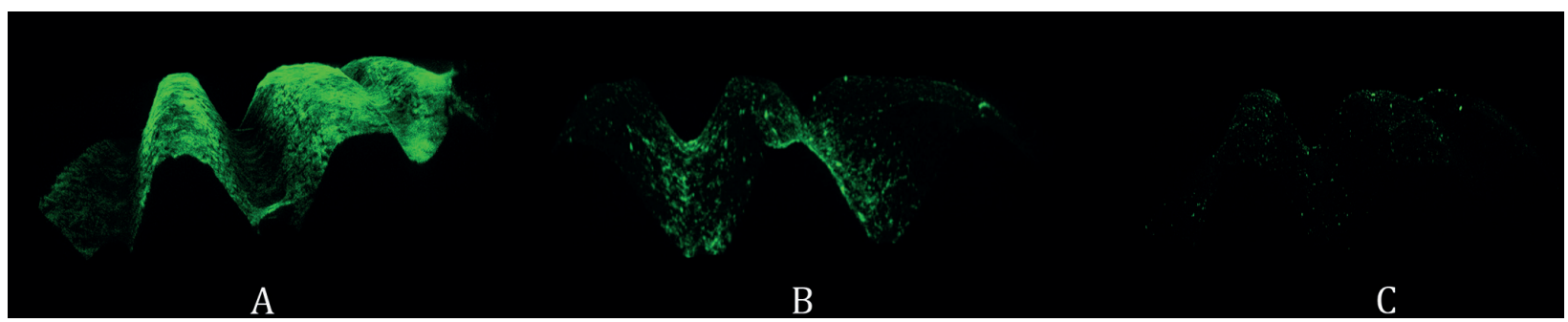

Fig. 4: Confocal microscopy images after 7 days of biofilm recolonization of the surface of a dental implant. A: Control group, B: Gauze group, C: Erythritol and chlorhexidine group. 
a patient. However, this oral biofilm included several bacterial species (multispecies) and was produced using a dynamic model (artificial mouth) that simulated real crevicular flow conditions. Thus, this method overcomes most of the limitations of the static in vitro biofilm traditionally employed $(15,17)$. Moreover, using PMA-qPCR provides important information, since it determines the bacterial count of live microorganisms present in the biofilm. Secondly, the therapies were applied under ideal conditions of accessibility and light. Certainly, this allowed the researcher to perform a more thorough decontamination of the implants in comparison with the standard clinical environment. For example, the lower areas of the implants' threads are usually more difficult to access with air-polishing systems, since a bone defect might prevent direct application of the powder in these zones (18). Nevertheless, this situation probably affected both active treatment groups equally and therefore did not favor one group over the other. Finally, some available antibiofilm treatments could not be included in the present study. Thus, future research should compare the disinfection properties of the erythritol-chlorhexidine formulation with those of other active therapies (Er:YAG laser, chlorhexidine solutions, glycine powder, among others).

Peri-implant diseases are the most prevalent biological complication associated with dental implants. The estimated prevalence of peri-implantitis ranges from $14 \%$ to $30 \%$, while mucositis affects $32 \%$ to $54 \%$ of patients (19). A recently-published private-practice sample with full-arch rehabilitations has shown that these figures might be even higher, as more than half of the patients were diagnosed with a peri-implant disease (20). According to the 2017 World Workshop on the Classification of Periodontal and Peri-Implant Diseases and Conditions (21), peri-implantitis is a plaque-associated pathological condition occurring in tissues around dental implants, characterized by inflammation in the periimplant mucosa and subsequent progressive loss of supporting bone. Initial bacterial colonization at implant surfaces occurs within 30 minutes, while a mature subgingival microbiota can be observed within a week (22). According to Cortés-Acha et al. (23), a wide variety of bacteria can be identified in healthy dental implants after 14 days of exposure to the oral environment. Also, a global plaque coverage of the implants is expected, even in the subgingival area (24). All this information highlights that plaque control and biofilm removal are paramount for preventing and treating these biological complications. Chemical and physical (mechanical or laser) decontamination strategies have been described in the literature (4). A meta-analysis to determine the most effective non-surgical therapy for the management of peri-implantitis concluded that local application of antibiotics, the use of glycine-powder applied with an air-polishing system, and Er:YAG laser seemed to significantly reduce soft tissue inflammation (bleeding on probing: BoP) (25). However, to the best of the present authors' knowledge there is no clear evidence that any mechanical or chemical biofilm decontamination technique is superior to others. This also seemed to be the case in the present sample, where the standard mechanical therapy (gauze with sterile saline) had a similar antibacterial effect to that of the erythritol-chlorhexidine treatment. However, this paper adds new and clinically relevant information regarding bacterial recolonization of a recently decontaminated dental implant surface. The selection of the most suitable decontamination therapy should take into consideration not only the immediate anti-biofilm effect but also its duration. Indeed, inhibition of bacterial regrowth after therapy might play a critical role in the prevention and progression of both mucositis and peri-implantitis. According to the results of the present study, erythritol-enriched powder with $3 \%$ of chlorhexidine seems to be a valid option for use in peri-implant maintenance programs, since it might inhibit colonization of the dental implants during the first days after treatment.

Air-polishing systems have been used in dentistry for several indications, some of which seek the removal of oral biofilms $(26,27)$. Some in vitro studies have shown that air-polishing sprays seem to achieve better biofilm removal outcomes than other mechanical systems (e.g., plastic curettes and vector system) or lasers (Er:YAG and $\mathrm{E}, \mathrm{Cr}: Y S G G)$ on micro-structured titanium surfaces (26). However, abrasive substances like sodium bicarbonate might cause undesirable alterations to implant surfaces (28-30). Glycine powder grants the same antibiofilm efficacy with minimal damage to the titanium, due to its low abrasiveness (29). Other agents that have also been tested include erythritol, which produces DNA and RNA depletion, attenuates extracellular matrix production, and alters dipeptide acquisition and amino acid metabolism, leading to inhibition of biofilm development (31). Erythritol has shown promising results under in vitro conditions, but also in real clinical scenarios. A recent randomized clinical trial has demonstrated the effectiveness of this powder in removing dental plaque during repeated instrumentation of residual pockets in supportive periodontal therapy (12). To summarize, erythritol seems to induce a change in the oral microbiota, shifting it towards a more favorable environment where the traditional colonizers are predominant (32). One possible explanation for these positive outcomes might be related to the attachment of erythritol/chlorhexidine particles to the dental implants. Indeed, implants from the ERY had $0.1 \mu \mathrm{m}$ particles attached to the implant surface. More studies are required to confirm that these particles have a clinically relevant effect. 
In conclusion, the use of erythritol powder with $3 \%$ chlorhexidine applied with an air polishing system seems to inhibit biofilm regrowth over recently decontaminated dental implants. However, this combination of erythritol/chlorhexidine seems to have a similar decontamination capacity of a simple mechanical removal (gauze with saline) in already established oral biofilms. Further studies are required to compare this formulation with other decontaminants and to validate the results of this in vitro study.

\section{References}

1. Suárez-López del Amo F, Yu SH, Wang HL. Non-surgical therapy for peri-implant diseases: a systematic review. J Oral Maxillofac Res. 2016;7:e13.

2. Zitzmann NU, Berglundh T. Definition and prevalence of periimplant diseases. J Clin Periodontol. 2008;35:286-91.

3. Schwarz F, Derks J, Monje A, Wang HL. Peri-implantitis. J Clin Periodontol. 2018; 45:S246-66.

4. Mellado-Valero A, Buitrago-Vera P, Solá-Ruiz MF, Ferrer-García JC. Decontamination of dental implant surface in peri-implantitis treatment: A literature review. Med Oral Patol Oral Cir Bucal. 2013; 18:e869-76

5. Singh S, Singh SK, Chowdhury I, Singh R. Understanding the mechanism of bacterial biofilms resistance to antimicrobial agents. Open Microbiol J. 2017;11:53-62.

6. Nogva HK,Dromtorp SM, Nissen H, Rudi K. Ethidium monoazide for DNA- based differentiation of viable and dead bacteria by 5'-nuclease PCR. Biotechniques. 2003;34:804-8.

7. Nocker A, Cheung CY, Camper AK. Comparison of propidium monoazide for differentiation of live vs. dead bacteria by selective removal of DNA from dead cells. J Microbiol Methods. 2006;67:310-20. 8. Rudi K, Moen B, Dromtorp SM, Holck AL. Use of ethidium monoazide and PCR in combination for quantifica-tion of viable and dead cells in complex samples. Appl Environ Microbiol. 2005;71:1018-24. 9. Cawthorn DM, Witthuhn RC. Selective PCR detection of viable Enterobacter Sakazakii cells utilizing propidium monoazide or ethidium bromide monoazide. Microbiology. 2008;105:1178-85.

10. Nocker A, Sossa-Fernández P, Burr MD, Camper AK. Use of propidium monoazide for live/dead distinction in microbial ecology. Appl Environ Microbiol. 2007;73:5111-7.

11. Esposito M, Grusovin MG, Worthington HV. Interventions for replacing missing teeth: treatment of peri-implantitis. Cochrane Collab. 2012;18:1-54.

12. Hägi TT, Hofmänner P, Salvi GE, Ramseier CA, Sculean A. Clinical outcomes following subgingival application of a novel erythritol powder by means of air polishing in supportive periodontal therapy: a randomized, controlled clinical study. Quintessence Int. 2013;44:753-61.

13. Drago L, Bortolin M, Taschieri S, De Vecchi E, Agrappi S, Del Fabbro M, et al. Erythritol/chlorhexidine combination reduces microbial biofilm and prevents its formation on titanium surfaces in vitro. J Oral Pathol Med. 2017;46:625-31.

14. Moharrami M, Perrotti V, Iaculli F, Love RM, Quaranta A. Effects of air abrasive decontamination on titanium surfaces: A systematic review of in vitro studies. Clin Implant Dent Rel Res. 2019;21:398-421.

15. Blanc V, Isabal S, Sánchez MC, Llama-Palacios A, Herrera D, Sanz $\mathrm{M}$, et al. Characterization and application of a flow system for in vitro multispecies oral biofilm formation. J Periodontal Res. 2014;49:323-32. 16. Àlvarez G, González M, Isabal S, Blanc V, León R. Method to quantify live and dead cells in multi-species oral biofilm by real-time PCR with propidium monoazide. AMB Express. 2013;3:1-8.

17. Vaughan BL, Smith BG, Chopp DL. The influence of fluid flow on modeling quorum sensing in bacterial biofilms. Bull Math Biol. 2010;72:1143-6.
18. Sahrmann P, Ronay V, Sener B, Jung RE, Attin T, Schmidlin PR. Cleaning potential of glycine air-flow application in an in vitro periimplantitis model. Clin Oral Implants Res. 2013;24:666-70.

19. Derks J, Tomasi C. Peri-implant health and disease. A systematic review of current epidemiology. J Clin Periodontol. 2015;42:S158-71. 20. Cercadillo-Ibarguren I, Sánchez-Torres A, Figueiredo R, Schwarz F, Gay-Escoda C, Valmaseda-Castellón E. Immediately loaded implant-supported full-arches: Peri-implant status after 1-9 years in a private practice. J Dent. 2017;67:72-6.

21. Berglundh T, Armitage G, Araujo MG, Avila-Ortiz G, Blanco J, Camargo PM, et al. Peri-implant diseases and conditions: Consensus report of workgroup 4 of the 2017 world workshop on the classification of periodontal and peri-implant diseases and conditions. J Periodontol. 2018; 89:S313-8.

22. Fürst MM, Salvi GE, Lang NP, Persson GR. Bacterial colonization immediately after installation on oral titanium implants. Clin Oral Implants Res. 2007;18:501-8.

23. Cortés-Acha B, Figueiredo R, Seminago R, Roig FJ, Llorens C, Valmaseda-Castellón E. Microbiota analysis of biofilms on experimental abutments mimicking dental implants: An in vivo model. J Periodontol. 2017;88:1090-104.

24. Cortés-Acha B, Figueiredo R, Blanc V, Soler-Ollé A, León R, Valmaseda-Castellón E. Development and viability of biofilms grown on experimental abutments mimicking dental implants: An in vivo model. Med Oral Patol Oral Cir Bucal. 2019;24:e511-7.

25. Muthukuru M, Zainvi A, Esplugues EO, Flemmig TF. Non-surgical therapy for the management of peri-implantitis: A systematic review. Clin Oral Implant Res. 2012;23:77-83.

26. Mensi M, Cochis A, Sordillo A, Uberti F, Rimondini L. Biofilm removal and bacterial re-colonization inhibition of a novel erythritol/chlorhexidine air-polishing powder on titanium disks. Materials (Basel). 2018;11:1-13.

27. Drago L, Del Fabbro M, Bortolin M, Vassena C, De Vecchi E, Taschieri S. Biofilm removal and antimicrobial activity of two different air-polishing powders: An in vitro study. J Periodontol. 2014;85:e363-9.

28. Schmidt KE, Auschill TM, Heumann C, Frankenberger R, Eick $\mathrm{S}$, Sculean A, et al. Influence of different instrumentation modalities on the surface characteristics and biofilm formation on dental implant neck, in vitro. Clin Oral Implants Res. 2017;28:483-90.

29. Cochis A, Fini M, Carrassi A, Migliario M, Visai L, Rimondini L. Effect of air polishing with glycine powder on titanium abutment surfaces. Clin Oral Implants Res. 2013;24:904-9.

30. Matsubara VH, Leong BW, Leong MJL, Lawrence Z, Becker T, Quaranta A. Cleaning potential of different air abrasive powders and their impact on implant surface roughness. Clin Implant Dent Relat Res. 2020;22:96-104.

31. Hashino E, Kuboniwa M, Alghamdi SA, Yamaguchi M, Yamamoto R, Cho H, et al. Erythritol alters microstructure and metabolomic profiles of biofilm composed of Streptococcus gordonii and Porphyromonas gingivalis. Mol Oral Microbiol. 2013;28:435-51.

32. Janus MM, Volgenant CMC, Brandt BW, Buijs MJ, Crielaard W, Zaura E, et al. Effect of erythritol on microbial ecology of in vitro gingivitis biofilms. J Oral Microbiol. 2017;9:1337477.

\section{Acknowledgements}

The authors wish to thank Mary Georgina Hardinge (Native English freelance translator) for English language editing of the manuscript, Dentaid SL (Cerdanyola del Vallès, Spain) for the help with the microbiology analysis, EMS (Nyon, Switzerland) for providing the air-flow device, and Avinent (Santpedor, Spain) for donating the implants for the study.

\section{Funding}

The authors declare non-financial support from EMS (Nyon, Switzerland), Dentaid SL (Cerdanyola del Vallés, Spain) and Avinent (Santpedor, Spain) for this study. The present research was conducted by the Dental and Maxillofacial Pathology and Therapeutics research group at the IDIBELL Institute (L'Hospitalet de Llobregat, Spain). 


\section{Conflict of interest}

The authors would like to declare the following interests outside the work presented:

Patricia Amate-Fernández reports no additional conflicts of interest. Rui Figueiredo reports grants, personal fees (sponsored lectures) and non-financial support from MozoGrau (Valladolid, Spain) and Avinent SA (Santpedor, Spain), grants and non-financial support from Dentaid SA (Cerdanyola del Vallès, Spain), personal fees (sponsored lectures) from BioHorizons Ibérica (Madrid, Spain), Inibsa Dental (Lliça de Vall, Spain), Dentsply implants Iberia (Barcelona, Spain) and Araguaney Dental (Barcelona, Spain) outside the sub-mitted work. Rui Figueiredo has also participated as a principal investigator in a randomized clinical trial sponsored by Mundipharma (Cambridge, UK) and in another clinical trial as a sub-investigator for Menarini Richerche (Florence, Italy).

Eduard Valmaseda-Castellón reports personal fees (sponsored lectures) and non-financial support from MozoGrau (Valladolid, Spain) and Avinent SA (Santpedor, Spain), grants and non-financial support from Dentaid SL (Cerdanyola del Vallès, Spain), and personal fees (sponsored lectures) from BioHorizons Ibérica (Madrid, Spain), Inibsa Dental (Lliça de Vall, Spain) and Dentsply implants Iberia (Barcelona, Spain) outside the submitted work. In addition, Eduard ValmasedaCastellón has also participated as a sub-investigator in a randomized clinical trial spon-sored by Mundipharma (Cambridge, UK). Vanessa Blanc, Gerard Àlvarez and Rubén León are researchers from the Dentaid Research Center (Dentaid, Cerdanyolla del Vallès, Spain).

\section{Ethics}

Not applicable since this study has an in vitro design. Thus, an ethics approval is not necessary.

\section{Authors contributions}

Patricia Amate-Fernández: Design of the study; acquisition and interpretation of the data, drafting of the article, approval of the final version of the manuscript and agreement to be accountable for all aspects of the work. Rui Figueiredo: Conception and design of the study, analysis and interpretation of the data, drafting of the manuscript, approval of the final version of the manuscript and agreement to be accountable for all aspects of the work.; Vanessa Blanc: Design of the study; analysis and interpretation of the data, critical revision of the manuscript, approval of the final version of the manuscript and agreement to be accountable for all aspects of the work. Gerard Àlvarez: Acquisition of the data, drafting of the article, approval of the final version of the manuscript and agreement to be accountable for all aspects of the work.; Rubén León: Design of the study, interpretation of the data, critical revision of the manuscript, approval of the final version of the manuscript and agreement to be accountable for all aspects of the work.; Eduard Valmaseda-Castellón: Conception and design of the study; analysis and interpretation of the data, critical revision of the manuscript, approval of the final version of the manuscript and agreement to be accountable for all aspects of the work. 